\title{
ANALYSIS OF THE COPPER-CHROMIUM BASED ELECTRODE DEFORMATION DURING RESISTANCE SPOT WELDING PROCESS
}

\author{
C. NACHIMANI \\ Department of Mechanical Engineering, Faculty of Engineering, University of Malaya \\ 50603, Kuala Lumpur, Malaysia. E-mail: nachicharde@yahoo.com
}

\begin{abstract}
This research presents an experimental investigation of the RMWA class two $(\mathrm{Cu}-\mathrm{Cr})$ electrode caps in resistance spot welding of carbon and stainless steels. A pair of equal-size circled-electrode caps $5 \mathrm{~mm}$ diameter is committed to weld up to 900 welding processes. The electrode caps are sharpened once in the meantime and are replaced using electrode dresser after underwent approximately 400 weld attempts. The degrading factors of $\mathrm{Cu}-\mathrm{Cr}$ electrodes have directly influenced the weld geometries on carbon and stainless steels while affected the bonding strength implicitly. The electrode caps that performed up to 900 weld attempts have been underwent the microstructural analytical observation, and several cracks in its internal structure were found. The internal cracks are only appeared in the movable-upper electrode cap due to continuous heating and hitting effects by pneumatic pressures, to compared with static-lower electrode in the $75 \mathrm{kV}$.A spot welder. Mushroom growth of electrode cap tips is another threat to weld surfaces as it reduces the process resistances during welding. In this experiment, the mushroom growth is seemed to be higher on upper side electrode than the lower side one. With increased diameter of electrode tip areas due to mushrooming effect, the weld geometries become odds which lead to inconsistency in its appearances and pave the way for expulsions. 21 Ref., 9 Figures.
\end{abstract}

$\boldsymbol{K} \boldsymbol{e} \boldsymbol{y} \boldsymbol{w} \boldsymbol{o r d} \boldsymbol{s}:$ spot welding, electrode mushroom, electrode degrading, electrode deterioration

Joining the carbon and stainless steels by spot welding is widely recommended by using class two alloys of Resistance Welder Manufacturers Association (RMWA) [1]. The ground for this sort of recommendations is their superior resistance, heat toleration and high corrosive opponent [2]. Without the mixture of substances, a pure copper is intrinsically soft and fails prematurely in demanding applications [3]. Mixture of substances is, therefore, a good choice for the manufacturing of electrode caps as to produce superior qualities, specifically for the mechanical and electrical properties. So, with this consideration in mind, $\mathrm{Cu}-\mathrm{Cr}$-based electrode caps are practically tested in welding approximately 900 weld pairs on carbon and stainless steels sheets in this experimental work.

Figure 1 shows the $\mathrm{Cu}-\mathrm{Cr}$ phase diagram for $\mathrm{Cu}$-based alloys [4]. It shows that chromium is easily soluble in the liquidus of copper when heated above 1076 and below $1860{ }^{\circ} \mathrm{C}$. Once the compound is solidified, it requires equal amount of heat to remelt it again [5]. This factor, now, creates significance in welding of carbon and stainless steels because the carbon steel melting point falls between 1426 to $1540{ }^{\circ} \mathrm{C}$, and that of

(c) C. NACHIMANI, 2015 stainless steel is $1400-1450{ }^{\circ} \mathrm{C}$. Copper and chromium solubility phases are actually of the eutectic type. The face-centered cubic (FCC) lattice will be formed in copper while body-centered cubic (BCC) one will be formed in chromium, when solidification process is concerned in $\mathrm{Cu}-\mathrm{Cr}$ alloy.

Fundamentally the welding process is varied by its process parameters (welding current, welding time, electrode tip diameters and electrode force) [6]. These parameter variations establish the corresponding heat growth for any materials as for which the bonding strengths are mainly anticipated. By doing so, the amount of heat that produce in an enclosed areas of electrode tips will cause the electrode tip deteriorations. Another factor that obviously affecting the electrode tip deteriorations is the electrode pressing forces, which is primarily supplied by the pneumatic pressure in this research. Thus, every time when electrodes are pressed to hold the materials being welded together, the hitting effect of electrode tips towards the base metal results metal hitting effect or simply the hitting effect, subjected to its fatigue at last. So in this experiment the mushroom growth, degradation as well as deterioration is what examined for the $\mathrm{Cu}-\mathrm{Cr}$ electrode caps using $75 \mathrm{kV} \cdot \mathrm{A}$ spot welder. Part of this research works have been previously published for the simulation, tensile shear strength, hardness distribution and metallurgical analysis, and 
therefore, such information is excluded in this paper but relevant references are given by [7].

Experimental. The base metals were prepared in rectangular shape with length of $200 \mathrm{~mm}$, width $25 \mathrm{~mm}$ and thickness $2 \mathrm{~mm}$. Chemical elements in stainless steel sheets were, wt.\%: $0.046 \mathrm{C}, 18.14 \mathrm{Cr}, 8.13 \mathrm{Ni}, 1.205 \mathrm{Mn}, 0.506 \mathrm{Si}$, $0.004 \mathrm{~S}, 0.051 \mathrm{~N}$ and $0.03 \mathrm{P}$. Carbon steel sheets have the following chemical composition, wt.\%: $0.23 \mathrm{C}, 0.095 \mathrm{Mn}, 0.006 \mathrm{Si}, 0.05 \mathrm{~S}$ and $0.04 \mathrm{P}$. Hardness of austenitic stainless steels was $H R B 86.2$, for the carbon steel it was about $H R B$ 65. A pair of water-cooled $(41 / \mathrm{min})$ truncated-cone electrodes with $5 \mathrm{~mm}$ of round diameter was applied to join these base metals (Figure 2).

\section{Properties of $\mathrm{Cu}-\mathrm{Cr}$ electrodes}

CMW alloy (class 2)

Chemical elements, wt.\% 18200 $0.05 \mathrm{~Pb}, 0.6 \mathrm{Cr}, 0.1 \mathrm{Si}$

Rockwell hardness $H R B$ .................... 70

Electrical conductivity $\% \ldots$

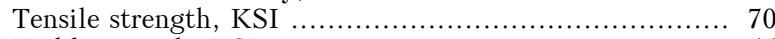

Yield strength, KSI …….................................... 55

Elongation, \% in 2 inch ................................. 21

Thermal conductivity, $\mathrm{W} / \mathrm{m} \cdot \mathrm{K}(\mathrm{min}) \quad \ldots \ldots \ldots \ldots \ldots \ldots \ldots \ldots . \ldots 187_{6}$

Thermal expansion, $/ \mathrm{K}$............................. 9. $9.8 \cdot 10^{-6}$

Approximately 900 welding attempts were made, and the electrode caps were sharpened once to remove the mushrooms after completed about 400 welding attempts. The electrode caps are then removed from the holder and cut at the line of its diameter (middle) using abrasive cutter to form flat surfaces. Once it has been cut across the diameter, it was mounted using resin powder on hot press mount-machine, such as way that it shows the cross sectional view of the electrode caps. The mounted samples were thereafter polished well using silicon papers, graded as $1200 / 800 p$ and $600 / 200 p$, and also continuously polished using Metadi polishing cloth. This polishing process has been conducted about $30 \mathrm{~min}$ to $1 \mathrm{~h}$ on each sample until the shining (mirrorlike) surfaces are seen. The V2A etchant that consists of $100 \mathrm{ml}$ water, $100 \mathrm{ml}$ hydrochloric acid and $10 \mathrm{ml}$ nitric acid is used to etch the polished samples. It was immersed into a box for about 45-60 min. After that the samples were well-rinsed off using plain water; dried using air blower; applied anti-corrosion liquid and kept in vacuum chamber for SEM observation. These preparatory steps and the above listed polishing materials are good enough to get reasonable micro- and macrographs for analytical purpose.

Results and discussion. Weld nuggets for carbon, stainless and mixed steels. Classical concerns about spot welding of carbon and stainless steels are, of course, rely on the dissimilarity of
$T,{ }^{\circ} \mathrm{C}$



Figure 1. $\mathrm{Cu}-\mathrm{Cr}$ phase diagram

melting points in individual weld joints and also the heat imbalances in the dissimilar weld joints [7]. In this experiment, both issues have been observed for several combinations of process parameters, for example, variations of welding current levels against variations of welding time cycles have been monitored [7]. Figures 3-5 show the carbon, stainless and both steels mixed welds made using $\mathrm{Cu}-\mathrm{Cr}$ electrode caps, respectively. Right sides in Figures represent the corresponding SORPAS simulations, in which the maximized temperatures are clearly shown before the solidification processes started, where as the left sides show the real welds after solidification processes are utterly done. Color representations are
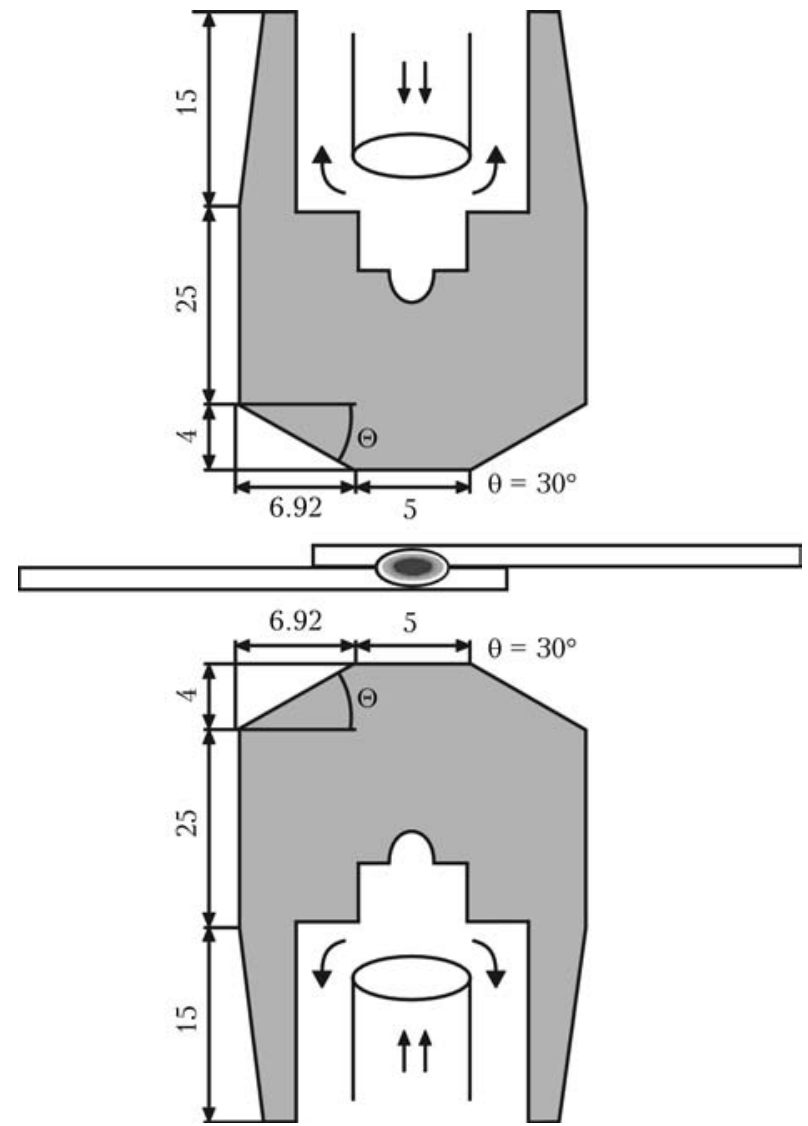

Figure 2. Dimension of electrodes on materials to be welded 


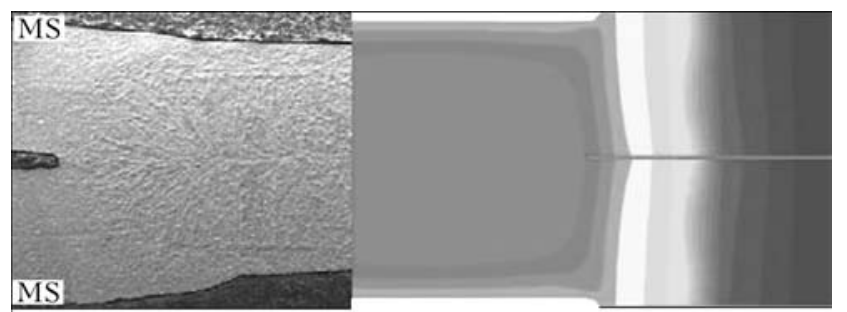

$1.740 \cdot 10^{2} \quad 4.820 \cdot 10^{2} \quad 7.900 \cdot 10^{2} \quad 1.098 \cdot 10^{3} \quad 1.406 \cdot 10^{3}$

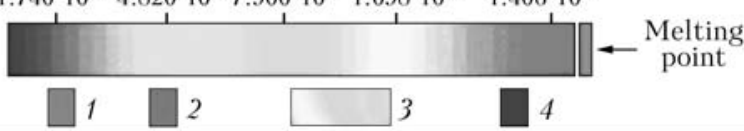

Figure 3. Temperature distribution in carbon steel weld (real vs simulation) (here and Figures 4, 5: 1 - fusion zone; 2 - HAZ; 3 - HEZ; 4 - base metal)

used to interpret the molten zones and also its vacinities, as to distinguish the heat-affected and also the heat-extended zones vividly. General point is that the $\mathrm{Cu}-\mathrm{Cr}$ electrode caps have significantly contributed for the formation of sound welds in carbon, stainless and mixed materials but in long run, it deteriorates itself.

Electrode mushrooming effect and chemical changes. The class two spot welding electrode caps are primarily made of copper and chromium materials as major components according to RMWA clasiffication [8]. It has dual phase mixture of chromium and alpha-copper as major chemical elements although it has other minor ones. The changes in properties happen at the rise of temperature $\left(Q=I^{2} R t\right)$ due to precipitation of chromium out of the solid solution. Literally, when the electrode is heated together with metals, it has high tendency of forming new kind of alloys [9, 10]. This is where the precipitation of chromium out of the solid solution is easily noticed [11, 12]. This has also been confirmed in the microstructural view of electrode caps (Figure 6). As welding processes are repeatedly being carried out on carbon and stainless steels, the mushrooming effect are growing due to heat exposure at the electrode tip surfaces. It is nothing but simply enlarging the areas $A$ of the cap tips, on the other end, causing the drop of contact resistance $(R=p l / A)$ adverse to efficient welding processes $[13,14]$. In this research, the electrode tip of both sides was originally $5 \mathrm{~mm}$ in

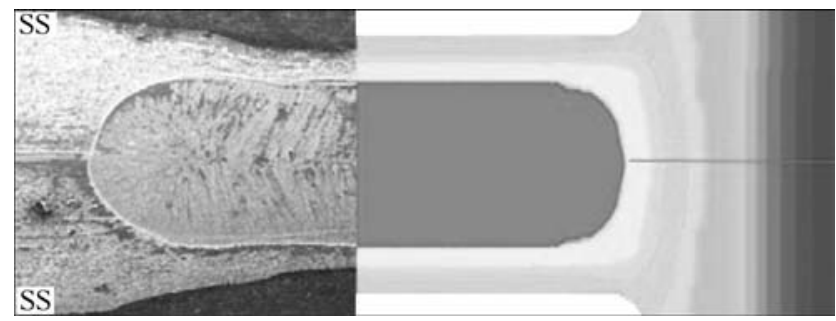

Figure 4. Temperature distribution in stainless steel weld (real vs simulation)

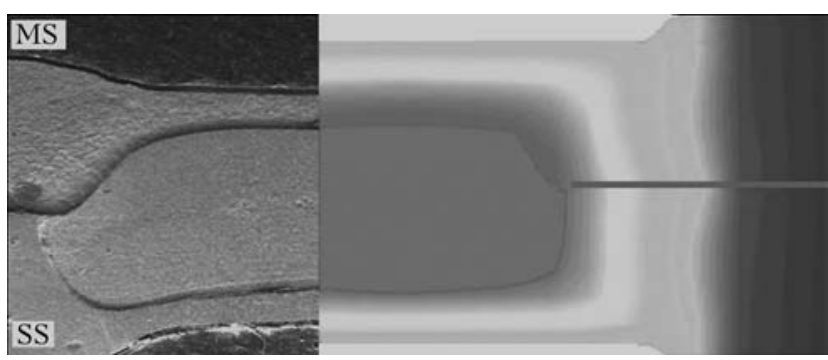

Figure 5. Temperature distribution in carbon and stainless steel dissimilar weld (real vs simulation)

diameter and it was partially-mushroomed. Literally the upper electrode tip diameter was enlarged up to $7.458 \mathrm{~mm}$ whereas the lower electrode tip diameter was enlarged up to $7.238 \mathrm{~mm}$. Figure 7 shows the deterioration of electrode tips which were engaged to weld about 900 times.

Having considered the deterioration that happen on the electrode caps after underwent 900 welding attempts, it was scanned for the profound structural changes. Point $A$ in Figure 6 represents the cap tip, at which the base metal molten heat $\left(\max \approx 1600{ }^{\circ} \mathrm{C}\right.$ ) was directly exposed. Points $B$ and $C$ are the following points
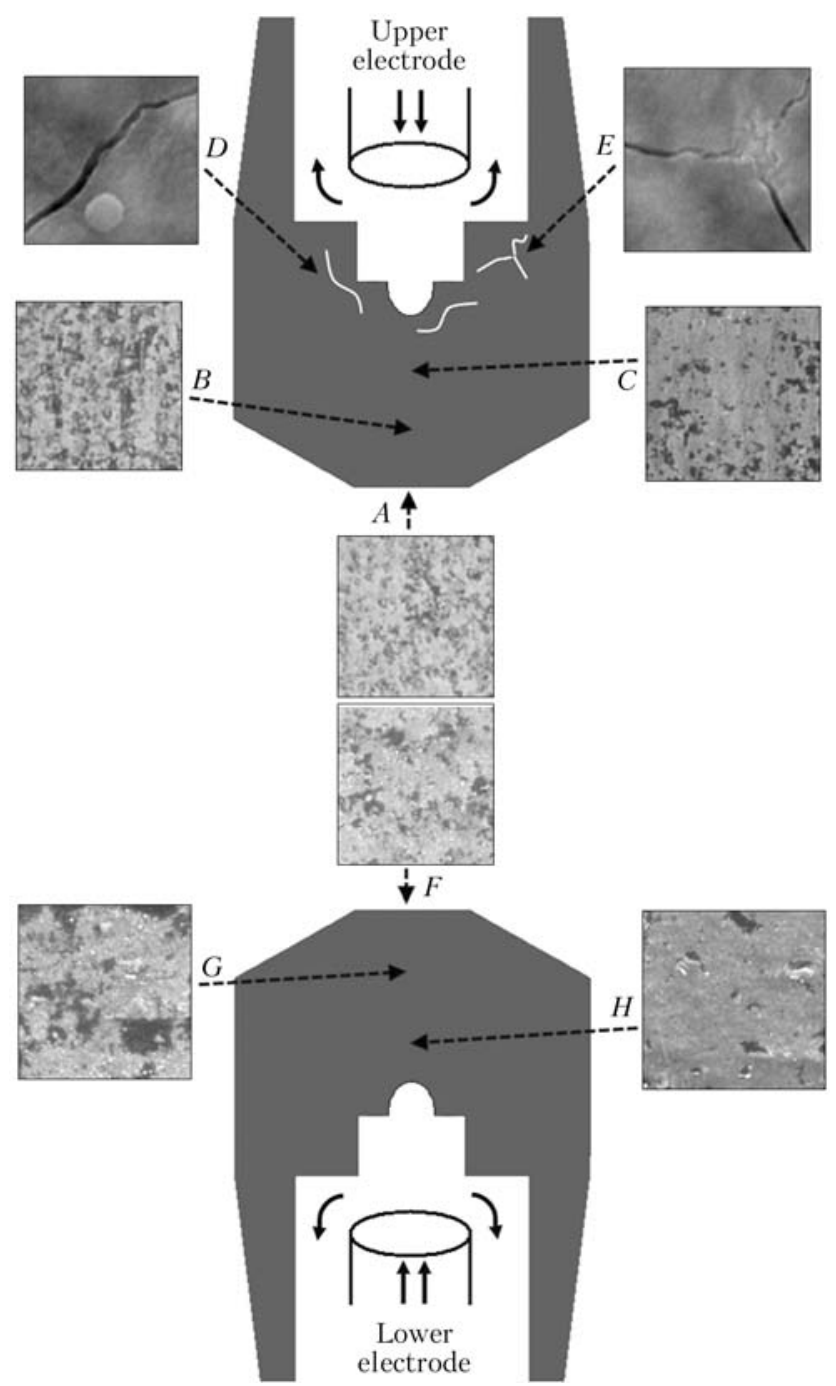

Figure 6. Electrode microstructural view 
lead to the way to electrode holder, which are also exposed to thermal flow but cooled by internal water flowing. Thus, chromium-to-copper ratio is gradually diminished from point $A$ to point $C$. The microstructural views reveal that the chromium precipitation is higher at the cap tip (point $A$ ) due to direct exposure of heat, which is above the threshold of melting points of $\mathrm{Cu}-\mathrm{Cr}$ alloys (see Figure 1). Point $B$ was, somehow, balanced of chromium-to-copper ratio, which is located between points $A$ and $C$. However, the difference of cooling rates at point $C$ due to water coolant $(4 \mathrm{l} / \mathrm{min})$ that flowing inside the electrode holders prevents chromium precipitation but resulted in internal cracks on the upper electrode cap. Lower electrode cap has similar effects (points $F, G$ and $H$ in Figure 6) that of the upper electrode cap had in terms of chemical properties changes but no internal crack is found because of its position as static during the welding process. Theoretically, the heated and cooled tip surfaces encounter the similar experiences that of annealing and quenching process caused in metal processing [15]. Annealing in $\mathrm{Cu}-\mathrm{Cr}$ alloy can induce ductility over time [16]. Chemical distribution for $\mathrm{Cu}-\mathrm{Cr}$ alloy has been graphically compared for both electrode caps and found similar patent of gradual precipitation of chromium out of the solid solution.

The electrode tip diameter was measured for every 100 weld attempts and it has been shown in Figure 8 to visualize the tip enlargement. The upper electrode cap mushrooming effect is slightly higher than the lower one because it has to bear the pressing forces (impact) while the squeezing process takes place every time. The severe deformation of electrode tips was noticed after underwent the first mushroom cleaning process. The diameter of tip was increased beyond $7 \mathrm{~mm}$ after underwent 900 welding attemps for which it requires the increments of the combination of process controlling parameters (i.e. welding current, welding time and electrode force) [17].

Hardness distribution. Spot welding process reduces the hardness of the $\mathrm{Cu}-\mathrm{Cr}$ electrode caps over time, particularly at the tip areas. This is possible because both the electrode tips are always working on the encapsulation of heat generation as for the weld formation [18]. Once the faying surfaces of metals are fused together and formed new composite of phases or so, the electrode caps ensure that the holding force is enough to avoid any escape of molten metals or to avoid over pressure at the molten areas [19]. So this behaviour is clearly subjected to the closed contact with metals being welded without producing

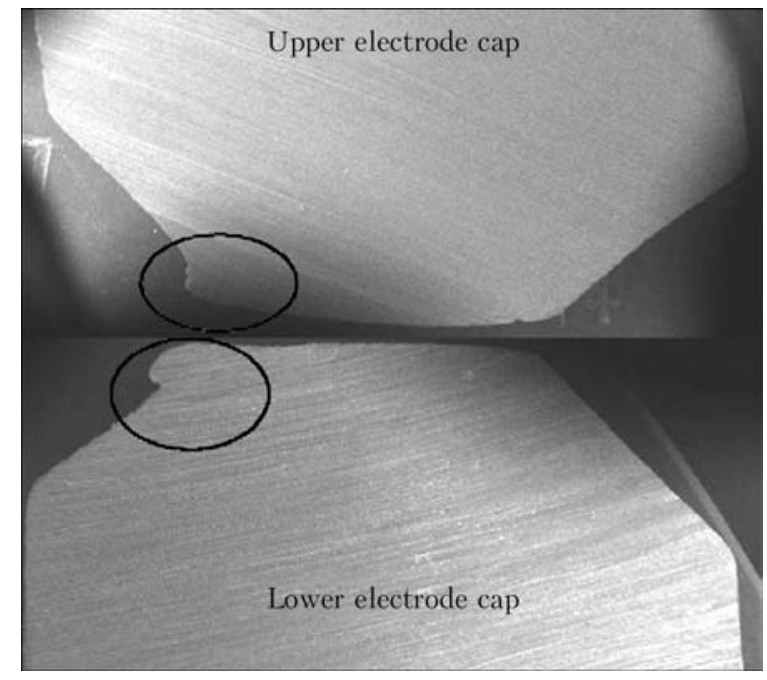

Figure 7. Macrograph view of electrode caps after underwent one-sided detoriaration

asperity [20]. Here, the hardness is what matters for, and hence both, the upper and lower electrode caps are measured for hardness distributive patterns. Hardness distribution is shown in $\mathrm{Fi}^{-}$ gure 9 as 10 measuring points are considered for each of the electrode caps separately. The $30^{\circ}$ truncated electrode caps are then measured along the cone areas approximately for the first $4 \mathrm{~mm}$ of distance (see $a$ and $b$ in Figure 9). Meanwhile the letter $A$ and $B$ represent the vanished portions and thereby no results found for these portions. It should be certainly noted once again here that the average hardness of brand new, class two $\mathrm{Cu}-\mathrm{Cr}$ alloy is around $H R B 70$. This value is significantly reduced at the tip areas and ascending gradually with increase of distance from tips towards its rear portions. This pattern (see Figure 9) supports the previous findings that the chromium precipitation is higher at the tips, as long as the rear portions are compared regardless of upper or lower position of electrode place-

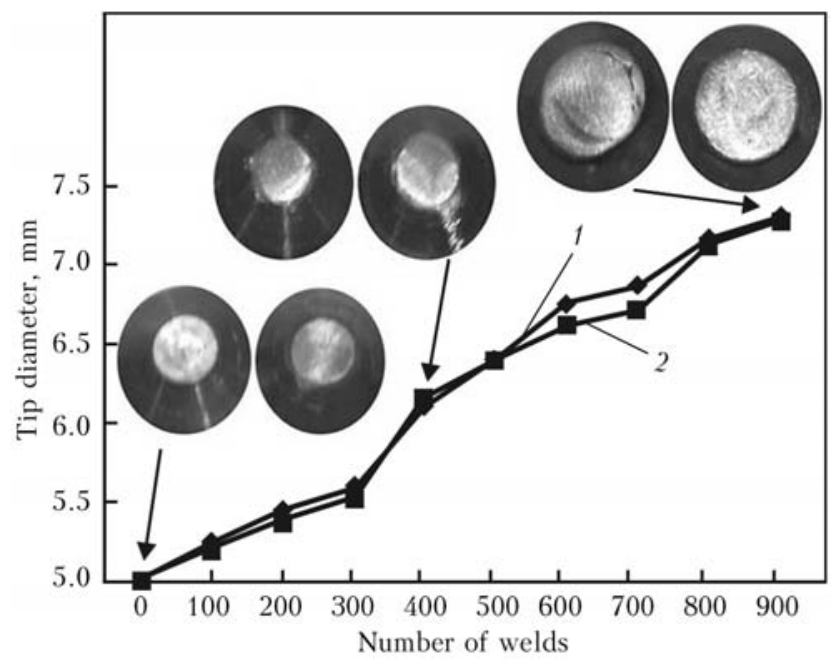

Figure 8. Electrode cap physical changes due to mushroom cleaning process: 1 - upper tip; 2 - lower tip 


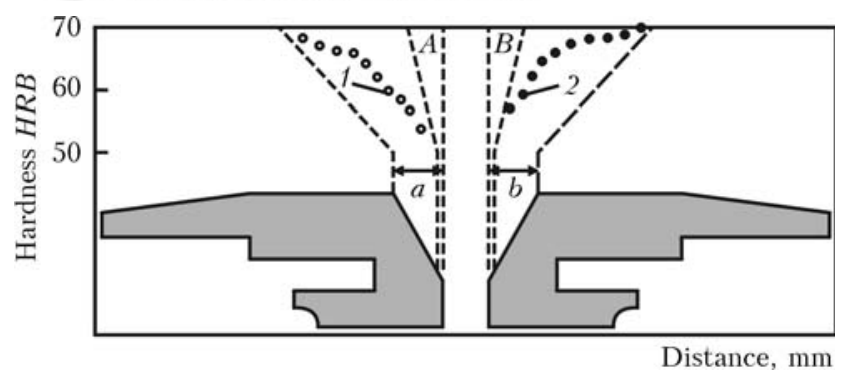

Figure 9. Electrode cap hardness distribution after 900 weld attempts: 1,2 - points of hardness measurement of upper and lower electrode cap, respectively; $A \approx 0.22 ; B \approx 0.21$; $a, b=4 \mathrm{~mm}$

ments. However, the hardness reduction is still slightly higher in upper electrode cap as compared to lower one. So, with this magnitude of analysis, a conclusion is drawn that the hardness of electrode cap tips $(\mathrm{Cu}-\mathrm{Cr}$ alloy) reduce and deform themselves over number of repetitive welding processes in welding carbon, stainless and mixed steels [21].

\section{Conclusions}

1. Precipitation of chromium out of the solid solution is higher at the electrode cap tips, as compared to its rear portions. This happens due to the frequent encapsulation of heat generation for the spot weld formation.

2. Precipitation of chromium out of the solid solution leads to deterioration of tip surfaces as well as degrading themselves.

3. Initial welding processes up to 400 times increases the electrode tip diameter about $23 \%$ of its original value due to mushrooming effects.

4. Further welding processes up to 500 times more (after the initial 400 times) increase the electrode tip diameter to another $26 \%$ of altered value, even after the accomplishement of sharpening of electrodes are done.

5 . In overall, $49 \%$ of its original value $(5 \mathrm{~mm})$ of upper electrode tip diameter increment is noticed whereas the lower electrode tip diameter increment is about $44 \%$.

6. Hardness of the upper electrode cap tip is reduced to approximately $H R B 54$ as compared to its original value of $H R B 70$.

7. Hardness of the lower electrode cap tip is reduced to approximately $H R B 57$ as compared to its original value of $H R B 70$.

Acknowledgments. I would like to thank Ministry of Science, Technology and Innovation, Malaysia, for financial support during the experiment. This publication is a research contribution to University Malaya, Malaysia.
1. Bower, R.J., Sorensen, C.D., Eager, T.W. (1990) Electrode geometry in resistance spot welding. Welding J., 2, 45-51.

2. Babu, S.S., Santella, M.L., Peterson, W (2000) Modelling resistance spot welding electrode life. ORNL.

3. Yeung, K.S., Thornton, P.H. (1999) Transient thermal analysis of spot welding electrodes. Welding J., 1-6.

4. Chakrabarti, D.J., Laughlin, D.E. (1984) The chromium-copper ( $\mathrm{Cu}-\mathrm{Cr})$ system. Bull. of Alloy Phase Diagrams, 5(1).

5. Chen, Z., Zhou, Y., Scotchmer, N. (2005) Coatings on resistance welding electrodes to extend life. $S A E$ Int. . 1-4.

6. Nachimani, C. (2012) Effect of spot welding variables on nugget size and bond strength of 304 austenitic stainless steel $(2 \mathrm{~mm})$. Australasian Welding J., 57, 39-44

7. Nachimani, C., Farazila, Y., Rajprasad, R. (2014) Material characterizations of mild steels, stainless steels, and both steel mixed joints under resistance spot welding (2-mm sheets). Int. J. Advanced Manufact. Techn., 75(1-4), 373.

8. Rao, Z.H., Liao, S.M., Tsai, H.L. et al. (2009) Mathematical modeling of electrode cooling in resistance spot welding. Welding J., 111-119.

9. Elise, G., Denis, C., Philippe, R. et al. (2014) Numerical modelling of electrode degradation during resistance spot welding using $\mathrm{CuCrZr}$ electrodes. $J$. Materials Eng. and Perform., 23(5), 1593-1599.

10. Chang, B.H., Zhou, Y. (2003) Numerical study on the effect of electrode force in small scale resistance spot welding. J. Materials Proc. Techn., 139, 635-641.

11. Babu, S.S., Joseph, A. (2010) Carpenter long-life electrodes for resistance spot welding of aluminum sheet alloys and coated high-strength steel sheet. Automotive Lightweighting Materials, 229-236.

12. Luo, P., Dong, S., Xie, Z. et al. (2014) The effects of coating parameters on the quality of $\mathrm{TiB}-\mathrm{TiC}$ composite phase coating on the surface of $\mathrm{Cu}-\mathrm{Cr}-\mathrm{Zr}$ alloy electrode. Surface and Coatings Techn., 253, 132-138.

13. Li, Y.B., Wei, Z.Y., Li, Y.T. et al. (2013) Effects of cone angle of truncated electrode on heat and mass transfer in resistance spot welding. Int. J. Heat and Mass Transfer, 65, 400-408.

14. Bayraktar, E., Moiron, J., Kaplan, D. (2006) Effect of welding conditions on the formability characteristics of thin sheet steels: Mechanical and metallurgical effects. J. Materials Proc. Techn., 175, 20-26.

15. Primoz Podrzaj, Samo Simoncic (2014) A machine vision-based electrode displacement measurement. Welding in the World, 58, 93-99.

16. Wei, P.S., Wu, T.H. (2014) Effects of electrode contact condition on electrical dynamic resistance during resistance spot welding. Sci. and Techn. of Welding and Joining, 19(2), 173-180.

17. Wei, P.-Sh., Wu, T.-H., Chen, L.-J. (2013) Joint quality affected by electrode contact condition during resistance spot welding. IEEE Transact. on Components, Packaging and Manufact. Techn., 3(12), 2164-2173.

18. Aravinthan, A., Nachimani, C. (2011) Analysis of spot weld growth on mild and stainless steel $(1 \mathrm{~mm})$. Welding J., Aug., 143-147.

19. Pouranvari, M., Marashib, S.P.H. (2010) Failure mode transition in AHSS resistance spot welds. Pt 1: Controlling factors. Materials Sci. and Eng. A, 528, 8337-8343.

20. Feramuz, K. (2009) The effect of process parameter on the properties of spot welded cold deformed AISI 304 grade austenitic stainless steel. J. Materials Proc. Techn., 209, 4011-4019.

21. Dursun, O. (2008) An effect of weld current and weld atmosphere on the resistance spot weld ability of $304 \mathrm{~L}$ austenitic stainless steel. Materials and Design, 29, 597-603. 